\title{
Rate and Predictors of Adherence to Antiretroviral Therapy among Clients on Antiretroviral Therapy at Tepi Health Center, South-west Ethiopia
}

\author{
Tsion Debito ${ }^{1}$ and Serawit Deyno ${ }^{2^{*}}$ \\ ${ }^{1}$ School of Nursing, Mizan-Tepi University, Mizan, Ethiopia \\ ${ }^{2}$ Pharmacology Unit, School of Medicine, Hawassa University, Post Box No: 1560, Hawassa, Ethiopia
}

\begin{tabular}{|c|c|}
\hline Abstract & Article Information \\
\hline $\begin{array}{l}\text { improved quality of life of peoples living with HIV/AIDS. Maximum benefits can only be } \\
\text { achieved through maximum adherence. We designed this study to assess rate and predictors } \\
\text { of adherence to antiretroviral therapy at Tepi health center. A facility based cross-sectional } \\
\text { study was conducted through patient's self report using structured pre-tested questionnaires } \\
\text { and medical record of the clients in a total of } 341 \text { samples using systematic random sampling } \\
\text { technique. The data were collected from January } 1,2012 \text { to February } 15,2012 \text { in Tepi health } \\
\text { centre. The data was analyzed using SPSS version } 16 \text {. Multiple logistic regression model was } \\
\text { constructed to determine predictors of adherence. Self-reported dose adherence in the study } \\
\text { area was } 78.6 \% \text { and that of combined indicator was } 43.4 \% \text {. Positive predictors of adherence } \\
\text { includes alcohol drinking (AOR }=4.36,95 \% \mathrm{Cl}=2.03,9.35) \text {, and a belief of ART cures HIV } \\
(\mathrm{AOR}=1.95,95 \% \mathrm{Cl}=1.21,3.13) \text { while long-duration on HAART ( } \geq 49 \text { months) (AOR=0.29, } \\
95 \% \mathrm{Cl}=0.11,0.75) \text { was negative predictor. The adherence rate in this study was much less } \\
\text { than studies in many parts of Ethiopia. Interventions should target on reduction of alcohol use } \\
\text { and on imparting appropriate knowledge of HAART that will address false beliefs of "ART } \\
\text { cures HIV". } \\
\end{array}$ & $\begin{array}{l}\text { Received : 30-05-2014 } \\
\text { Revised : 16-09-2014 } \\
\text { Accepted : 19-09-2014 } \\
\text { Keywords: } \\
\text { Adherence } \\
\text { HAART } \\
\text { Rate and Predictors } \\
\text { HIV/AIDS } \\
\text { Combined Adherence } \\
\text { *Corresponding Author: } \\
\text { Serawit Deyno } \\
\text { E-mail: } \\
\text { dserawit@gmail.com }\end{array}$ \\
\hline
\end{tabular}

\section{INTRODUCTION}

Highly active antiretroviral therapy (HAART) is a breakthrough and celebrated in the reduction of mortality and in the improvement of quality of life of PLWHA. Since the introduction of HAART in 1995, important reduction in HIV progression to both AIDS and death is observed (Cooke, Lee et al. 2014; Dewing, Mathews et al., 2014). Antiretroviral therapy (ART) is designed to suppress viral replication and thus reduce the likelihood of development of drug resistant viral strain and also prevents further viral destruction of the cellular immune system (Edison Hughes et al., 2014).

Adherence to HAART is one of potentially alterable factors determining outcomes for patients with HIV (Lee Rand et al., 2014). However non-adherence to HAART is common in all groups of treated individuals (Tiyou Belachew et al., 2010; Maqutu Zewotir et al., 2011; Mirkuzie Hinderaker et al., 2011; Kebede and Wabe, 2012; Mengistu and Chere, 2012; Biressaw Abegaz et al., 2013; Arage Tessema et al., 2014; Mulu Liebert et al., 2014).To achieve goal of HAART maximal and durable viral suppression and successful HIV therapy requires adherence of $\geq 95 \%$ (Hassan, Nabwera et al., 2014). Failure rates increase sharply as adherence decrease (Edison Hughes et al., 2014).
Literature survey shows that, there are no studies conducted at health center level in Ethiopia where as a large segment of population is treated at health center. This study was therefore designed to determine the adherence rate and determinates of adherence to HAART among clients on ART in Tepi health center.

\section{MATERIALS AND METHODS}

\section{Study Area and Design}

Data was collected from January 1, 2012 to February 15, 2012 in Tepi health centre. Tepi health centre is located in Tepi town Sheka zone, SNNPR. Tepi town is 565 kilometers away from Addis Ababa (capital of Ethiopia) ART had been commenced in Tepi health center in 2005.

A facility based cross-sectional observational study was conducted through patient's self report using structured questionnaires and medical record of the clients. The study population was all PLWHA on HAART for at least three months and following their treatment follow-up from January 1, 2012 to February 15, 2012. Clients on treatment for less than 3 months, under the age of 18 years and with severe acute illness were excluded from the study. 


\section{Tsion Debito and Serawit Deyno}

\section{Sample Size and Sampling Technique}

A sample size was calculated using a similar study from Jimma University Specialized Hospital which has a combined self reported adherence rate of 72.49 . Single population proportion formula with $95 \%$ confidence interval was used and the sample size was calculated to be 341 . The sampled population was selected using simple random sampling technique.

\section{Data Collection Tool}

Data were collected on structured pre-tested questionnaire by interviewing clients and transferring clinical information such as CD4 cells, WHO Stage, duration on treatment and regimen from medical records. The questionnaire was adapted from studies from other Ethiopian studies (Tadios and Davey, 2006; Amberbir Woldemichael et al., 2008; Tiyou and Belachew et al., 2010; Emiru and Wakgari, 2014). The questionnaire was developed in English and translated to Amharic. The clients were interviewed for variables. Data collection was conducted at ART clinic of Tepi health center by trained health professionals. The questionnaire was pre-tested on $5 \%$ of study population and the data was not included in actual study.

Adherence status is a dependent variable while independent variables includes Socio-demographic and economic characteristics (age, sex, ethnic group, residence, distance from service facility, religion, education, employment, marital status, monthly income and having cell/public phone), clinical characteristics of the disease (WHO staging, CD4 count), duration on treatment and regimen type. Disclosure status, psychosocial support and substance and alcohol use, adherence to treatment information, attitudinal factors contributing for non-adherence was also assessed.

\section{Data Quality and Analysis}

The data was collected using structured pre-tested questionnaire under control of the investigator through trained data collectors five clinical nurses and a senior nurse supervising them. The completeness and logical consistency of the data was checked and corrected at the spot during data collection.

The collected data was edited, cleaned, coded and entered into Epi Info version 7 and then exported to SPSS version 16 for analysis. Finally data was summarized using descriptive statistics to assess basic client characteristics such as socio-demographic status and for the calculation of adherence rate. Predictors of adherence were determined using logistic regression. In bivariate analysis each independent variable was tested for the presence of association with the dependent variable. After bivariate analysis, final multivariate analysis was conducted.

Self reported dose adherence to all antiretroviral agents could be summarized as the ratio of the average daily number of antiretroviral medications adhered to total number of antiretroviral medication prescribed (Tadios and Davey, 2006). These can be written in the following way:

Adherence rate $=$ $=($ Number of doses prescribed-Number of doses missed $) \times 100$ Number of doses prescribed
Sci. Technol. Arts Res. J., July-Sep 2014, 3(3): 93-98

\section{Ethical Consideration}

The study proposal was approved by institutional ethical review committee of Hawassa University and Addis Continental Institute of Public Health. Permission obtained from Sheka zone health department and Tepi town administration health office to conduct the study. Informed consent obtained from every respondent before proceeding to the interview and the information is kept confidential.

\section{RESULT}

\section{Socio-demographic and Economic Characteristics}

A total of 341 study subjects were included in this study. The majority of the study participants were between the age group of $25-34$ about $146(42.8 \%)$ with mean (SD) of $35 \pm 9.6$ and a range of 50 . The rural population comprise $211(61.9 \%)$ of the study participants. 175 $(51.3 \%)$ of the study participants have less than $1 \mathrm{~km}$ distance from the health service facility. 209 (61.3\%) of the study subjects were Orthodox Christian, while the $14.7 \%$ Protestant and $24.0 \%$ Muslim. The whole sociodemographic data of the study participants were summarized in table 1.

Table 1: Socio-demographic \& Economic characteristics of ART clients in Tepi HC, $(n=341)$, Tepi 2012

\begin{tabular}{|c|c|c|}
\hline Variable & Number & Percent (\%) \\
\hline \multicolumn{3}{|l|}{ Age } \\
\hline $18-24$ & 28 & 8.2 \\
\hline $25-34$ & 146 & 42.8 \\
\hline $35-44$ & 111 & 32.6 \\
\hline $45+$ & 56 & 16.4 \\
\hline \multicolumn{3}{|l|}{ Sex } \\
\hline Male & 151 & 44.3 \\
\hline Female & 190 & 55.7 \\
\hline \multicolumn{3}{|l|}{ Residence } \\
\hline Urban & 130 & 38.1 \\
\hline Rural & 211 & 61.9 \\
\hline \multicolumn{3}{|l|}{ Distance } \\
\hline$<1 \mathrm{Km}$ & 175 & 51.3 \\
\hline $1-5 \mathrm{Km}$ & 44 & 12.9 \\
\hline $6-10 \mathrm{Km}$ & 62 & 18.2 \\
\hline$>10 \mathrm{Km}$ & 60 & 17.6 \\
\hline \multicolumn{3}{|l|}{ Educational level } \\
\hline No formal education & 96 & 28.2 \\
\hline $1-8$ & 189 & 55.4 \\
\hline $9-12$ & 37 & 10.9 \\
\hline $12+$ & 19 & 5.6 \\
\hline \multicolumn{3}{|l|}{ Marital status } \\
\hline Single & 42 & 12.3 \\
\hline Married & 161 & 47.2 \\
\hline Divorced & 86 & 25.2 \\
\hline Widowed & 47 & 13.8 \\
\hline Cohabitating & 5 & 1.5 \\
\hline \multicolumn{3}{|l|}{ Employment } \\
\hline Employed & 42 & 12.3 \\
\hline Unemployed & 299 & 87.7 \\
\hline \multicolumn{3}{|l|}{ Monthly Income } \\
\hline No source & 35 & 10.3 \\
\hline$<400$ & 189 & 55.4 \\
\hline $401-1000$ & 81 & 23.8 \\
\hline $1001-2000$ & 30 & 8.8 \\
\hline$>2000$ & 6 & 1.8 \\
\hline \multicolumn{3}{|l|}{ Cell/public phone } \\
\hline Yes & 182 & 53.4 \\
\hline No & 159 & 46.6 \\
\hline
\end{tabular}




\section{Tsion Debito and Serawit Deyno}

$216(63.3 \%)$ of the study participants believe taking ART reminds their HIV sero-status and 53(15.5\%) believe that taking ART continuously could harm them. About half of the study participants $51.3 \%$ believe "ART cures HIVIAIDS".

Majority $269(78.9 \%)$ of the study subjects were in WHO stage III during initiation while $2(0.6 \%)$ were on asymptomatic stage (stage I). Baseline CD4 cell count $<200$ cells $/ \mathrm{m}^{3}$ contributes for $137(40.2 \%$ ) and a CD4 range $350-500$ cells $/ \mathrm{m}^{3}$ about $16(4.7 \%)$, nearly $30 \%$ of the clients have no recorded baseline CD4 count. More than half $188(55.1 \%$ ) of clients has no recorded recent CD4 count either because of failure to record or were not totally measured. $60(17.6 \%)$ clients have a range of CD4 cell 200-350 cells $/ \mathrm{m}^{3} .91(26.7 \%)$ have been on HAART for 312 months, while $45(13.2 \%)$ for more than 49 months. Predominantly, $113(33.1 \%)$ of study participants were on regimen containing $\mathrm{D} 4 \mathrm{~T}+3 \mathrm{TC}+\mathrm{NVP}$, whereas $19(5.6 \%)$ were on TDF+ $3 T C+N V P$.

\section{Rate of Adherence and Reasons for Non-adherence}

Missed doses were assessed for "the day before", "past three days" (three days recall) and "past seven days" (seven days recall). $11.7 \%$ of clients missed at least a single dose of drug the day before, $17.9 \%$ missed at least a dose in three days recall, while 22.3 missed at least a dose in seven days recall as shown in table 2.

Table3 summarizes that $268(78.6 \%)$ of the participants were dose adherent, while $207(60.7 \%)$ were time/schedule adherent and $221(70.8 \%)$ were food adherent (follow the food restriction). The overall adherence (dose, time and food) calculated by using participants who were adherent in all (dose, time/schedule and food) was $148(43.4 \%)$.

Forgetting and being away from home are the major reasons for dose non-adherence as indicated in figure 1.
Sci. Technol. Arts Res. J., July-Sep 2014, 3(3): 93-98

Table 2: No. of Clients missed at least a tablet by selfreport in Tepi HC $(n=341)$

\begin{tabular}{lll}
\hline No. of days & Number & Percent (\%) \\
\hline The day before & & \\
$\quad$ Yes & 40 & 11.7 \\
$\quad$ No & 301 & 88.3 \\
$\begin{array}{l}\text { Past three days } \\
\quad \text { Yes }\end{array}$ & 61 & 17.9 \\
$\quad$ No & 280 & 82.1 \\
$\begin{array}{l}\text { Past seven days } \\
\text { Yes }\end{array}$ & 76 & 22.3 \\
$\quad$ No & 265 & 77.7 \\
\hline
\end{tabular}

Table 3: Self reported (dose, time, food and overall) adherence among ART clients in Tepi health center $(n=341)$, Tepi 2012.

\begin{tabular}{lcc}
\hline Variables & Number & Percent (\%) \\
\hline $\begin{array}{l}\text { Self reported 7-day } \\
\text { recall dose adherence }\end{array}$ & & \\
$\quad$ Adherent & 268 & 78.6 \\
$\quad$ Non-Adherent & 73 & 21.4 \\
Time(schedule) adherence & & \\
$\quad$ Adherent & 207 & 60.7 \\
$\quad$ Non-Adherent & 134 & 39.3 \\
Is there food restriction in & & \\
your regimen? & & \\
$\quad$ No & 312 & 91.5 \\
$\quad$ Yes & 29 & 8.5 \\
$\begin{array}{l}\text { Food adherence } \\
\text { (following restrictions) }\end{array}$ & & \\
$\quad$ Adherent & 221 & 70.8 \\
$\quad \begin{array}{l}\text { Non-Adherent } \\
\text { Over all adherence } \\
\text { (dose, time and food ) }\end{array}$ & 91 & 29.2 \\
$\quad$ Adherent & & \\
$\quad$ Non-Adherent & 148 & 43.4 \\
\hline
\end{tabular}

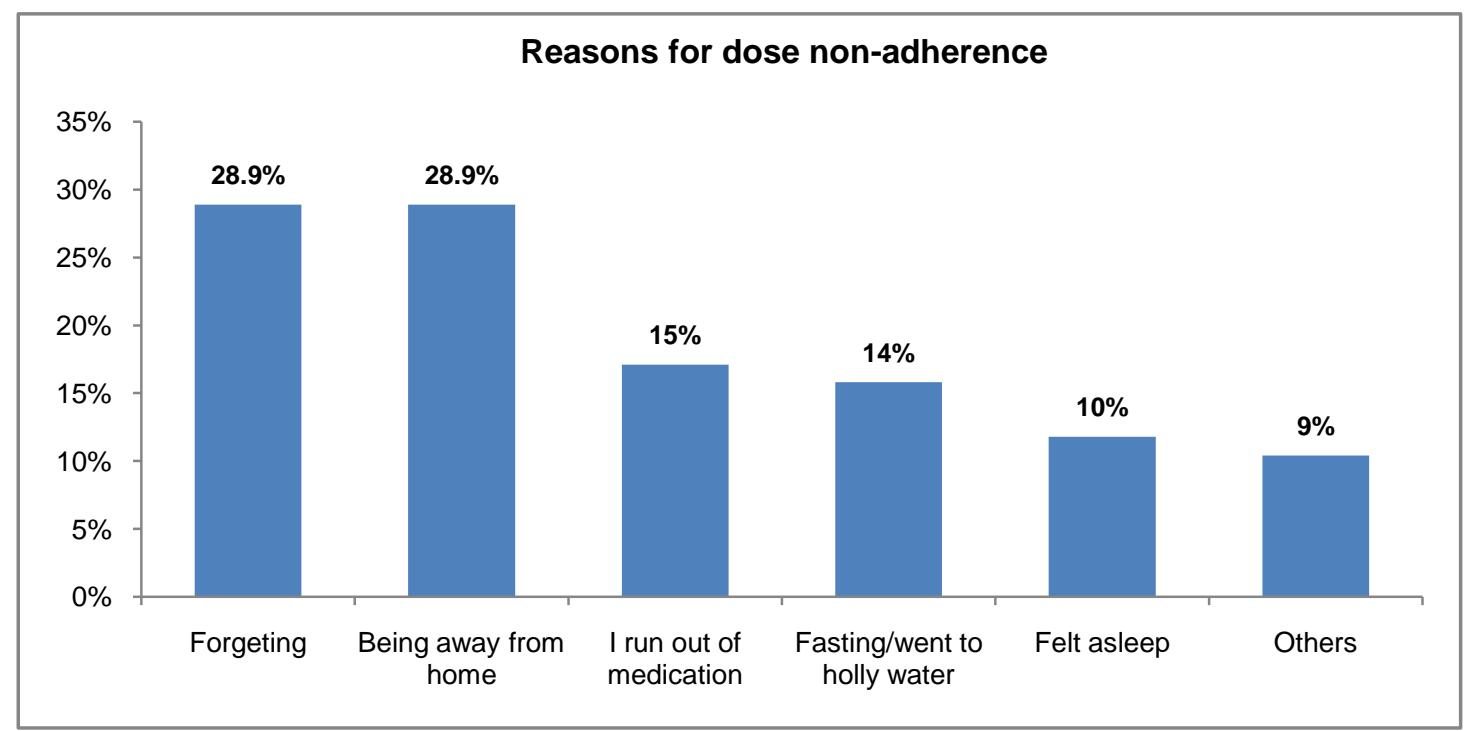

Figure 1: Reasons for dose non-adherence

\section{Predictors of Adherence}

In bivarate analysis each independent variables were tested with the overall adherence for association. Variables such as family support, alcohol use and a belief that "ART cures HIVIAIDS" were found to be significantly associated with the adherence. Family support was likely to increase adherence by odds of 1.8 times $(\mathrm{COR}=1.8$, $95 \% \mathrm{Cl}=1.07,3.01)$. Not using alcohol was likely to increase adherence by odds of 3.7 times (COR=3.69, $95 \% \mathrm{Cl}=1.83,7.41)$. Not having belief of "ART cures HIVIAIDS" was likely to increase adherence by odds of 1.7 times $(\mathrm{COR}=1.69, \mathrm{Cl}=1.10,2.61)$. 
Table 4: Predictors of ART adherence in Tepi health center $(n=341)$

\begin{tabular}{|c|c|c|c|c|}
\hline Variable & Adherent No. (\%) & Non-adherent No. (\%) & COR(95\%Cl) & AOR(95\% Cl) \\
\hline \multicolumn{5}{|l|}{ Age } \\
\hline $18-24$ & $61(41.8)$ & $85(58.2)$ & $1.78(0.713,4.457)$ & $1.37(0.49,3.79)$ \\
\hline $25-34$ & $50(45.0)$ & $61(55.0)$ & $1.11(0.591,2.081)$ & $0.83(0.41,1.69)$ \\
\hline $35-44$ & $22(39.3)$ & $34(60.7)$ & $1.27(0.659,2.436)$ & $1.04(0.50,2.16)$ \\
\hline $44^{+}$ & $15(53.6)$ & $13(46.4)$ & 1.00 & 1.00 \\
\hline \multicolumn{5}{|l|}{ Disclosure status } \\
\hline Yes & $136(44.7)$ & $168(55.3)$ & $1.69(0.82,3.48)$ & $0.94(0.36,2.46)$ \\
\hline No & $12(32.4)$ & $25(67.6)$ & 1.00 & 1.00 \\
\hline \multicolumn{5}{|l|}{ Family support } \\
\hline Yes & $28(32.9)$ & $57(67.1)$ & $1.80(1.07,3.01)$ & $1.92(0.96,3.83)$ \\
\hline No & $120(46.9)$ & $136(53.1)$ & 1.00 & 1.00 \\
\hline \multicolumn{5}{|l|}{ Alcohol use } \\
\hline Yes & $11(20.0)$ & $44(80.0)$ & 1.00 & 1.00 \\
\hline No & $137(47.9)$ & $149(52.1)$ & $3.69(1.83,7.41)$ & $4.36(2.03,9.35)$ \\
\hline \multicolumn{5}{|l|}{ "ART cure HIV" } \\
\hline Yes & $65(37.1)$ & $110(82.9)$ & 1.00 & 1.00 \\
\hline No & $83(50.0)$ & $83(50.0)$ & $1.69(1.10,2.61)$ & $1.95(1.21,3.13)$ \\
\hline \multicolumn{5}{|l|}{ WHO stage } \\
\hline Stage 1 & $1(50.0)$ & $1(50.0)$ & 1.00 & 1.00 \\
\hline Stage 2 & $19(32.2)$ & $40(67.8)$ & $0.46(0.03,8.01)$ & $0.45(0.23,8.71)$ \\
\hline Stage 3 & $122(45.4)$ & $147(54.6)$ & $0.83(0.51,13.41)$ & $0.98(0.05,18.0)$ \\
\hline Stage 4 & $6(54.5)$ & $5(45.5)$ & $1.20(0.59,24.47)$ & $1.85(0.08,45.0)$ \\
\hline \multicolumn{5}{|l|}{ Recent $\mathrm{CD}_{4} \mathrm{C}$. } \\
\hline No Data & $70(37.2)$ & $118(62.8)$ & $0.70(0.29,1.65)$ & $0.49(0.19,1.32)$ \\
\hline$>500$ cells $/ \mathrm{mm}^{3}$ & $20(58.8)$ & $14(41.2)$ & $1.69(0.59,4.65)$ & $1.76(0.49,6.23)$ \\
\hline $350-500 "$ & $18(51.4)$ & $17(48.6)$ & $1.25(0.44,3.55)$ & $0.85(0.26,2.80)$ \\
\hline 200- 350 " & $29(48.3)$ & $31(51.7)$ & $1.11(0.43,2.86)$ & $0.78(0.27,2.27)$ \\
\hline$<200$ & $11(45.8)$ & $13(54.2)$ & 1.00 & 1.00 \\
\hline \multicolumn{5}{|l|}{ Duration on HAART } \\
\hline 3-12 mo. & $46(50.5)$ & $45(49.5)$ & 1.00 & 1.00 \\
\hline $13-24 \mathrm{mo}$. & $34(44.2)$ & $43(55.8)$ & $0.77(0.42,1.42)$ & $0.90(0.45,1.82)$ \\
\hline $25-36 \mathrm{mo}$. & $28(41.2)$ & $40(58.8)$ & $0.69(0.36,1.29)$ & $0.53(0.25,1.13)$ \\
\hline 37-48mo. & $23(38.3)$ & $37(61.7)$ & $0.61(0.31,1.18)$ & $0.58(0.26,1.29)$ \\
\hline 49mo. & $17(37.8)$ & $28(62.2)$ & $0.59(0.29,1.23)$ & $0.29(0.11,0.75)$ \\
\hline \multicolumn{5}{|l|}{ Regimen } \\
\hline TDF+3TC+NVP & 12(63.2) & $7(36.8)$ & 1.00 & 1.00 \\
\hline $\mathrm{TDF}+3 \mathrm{TC}+\mathrm{EFV}$ & $25(41.0)$ & $36(59.0)$ & $0.41(0.14,1.17)$ & $0.44(0.14,1.33)$ \\
\hline $\mathrm{AZT}+3 \mathrm{TC}+\mathrm{NVP}$ & $32(50.8)$ & $31(49.2)$ & $0.60(0.21,1.73)$ & $0.69(0.22,2.19)$ \\
\hline $\mathrm{AZT}+3 \mathrm{TC}+\mathrm{EFV}$ & $12(41.4)$ & $17(58.6)$ & $0.41(0.13,1.35)$ & $0.45(0.12,1.66)$ \\
\hline $\mathrm{D} 4 \mathrm{~T}+3 \mathrm{TC}+\mathrm{NVP}$ & $45(39.8)$ & $68(60.2)$ & $0.39(0.14,1.11)$ & $0.58(0.19,1.77)$ \\
\hline $\mathrm{D} 4 \mathrm{~T}+3 \mathrm{TC}+\mathrm{EFV}$ & $22(39.3)$ & $34(60.7)$ & $0.38(0.13,1.11)$ & $0.45(0.14,1.44)$ \\
\hline
\end{tabular}

\section{Multivariate Analysis Result of Combined (Dose, Time and Food) Adherence}

Variables which were associated with the dependent variable $P<0.25$ and others that had been significant in the previous other studies were included in the model. All variables which were significant in bivariate analysis were also significant in multivariate model except family support. Duration on HAART was significant predictor in multivariate model. Not using alcohol was likely to increase adherence by odds of $4.36(\mathrm{AOR}=4.36,95 \% \mathrm{Cl}$ $=2.03,9.35$ ), not having belief of "ART cures from HIVIAIDS" was likely to increase adherence by odds of 2 (AOR $=1.95,95 \% \mathrm{Cl}=1.21,3.13)$ and long-duration on HAART ( $\geq 49$ months) decrease the odds of adherence by $70 \%(\mathrm{AOR}=0.29,95 \% \mathrm{Cl}=0.11,0.75)$.

\section{DISCUSSION}

The adherence status of clients to ART was assessed using patient self-report in this study; due to its simplicity, relatively inexpensive, and easy to implement in the patient's follow-up. It can also provide information about the reasons why a patient did or did not take the medication properly. This type of adherence measurement was used in many studies in Ethiopia independently without other supplementary methods (Tadios and Davey, 2006; Amberbir Woldemichael et al., 2008). This method has been shown to overestimate adherence both in the HIV setting and non-HIV setting and non-consistent results were found when compared to more objective measures (Michel Lionel et al., 2001). Selfreported non-adherence is suggestive of worse virologic control (Miller and Hays, 2000; Michel Lionel et al., 2001).

The adherence rate in this study was also presented using a combined (dose, time and food). Some studies use only dose adherence as a measurement 13, 14. Best adherence measurement has to assess whether or not dose is skipped, maintaining the scheduled time and food or dietary instructions agreed with the health provider to get the overall adherence rate. Recent studies prefer to use the combined measurement (Amberbir Woldemichael et al., 2008; Tiyou Belachew et al., 2010). 


\section{Tsion Debito and Serawit Deyno}

In this study the dose and food adherence were higher than the time adherence; unlike a study by Amberbir, Woldemichael et al. (2008). The rate of dose adherence in the study area was $78.6 \%$; which was lower than reported in Southwest Ethiopia (Deribe Hailekiros et al., 2008; Tiyou Belachew et al., 2010) and nearer to studies from Northwest Ethiopia (Tessema Biadglegne et al., 2010).

The overall rate of self reported adherence in this study area based on the combined indicators of the three adherence rates; dose, time and food was $43.4 \%$. There are few studies in Ethiopia used the three adherence errors (dose, time and food) to obtain the combined adherence rates (Amberbir Woldemichael et al., 2008; Markos Worku et al., 2008 and Tiyou Belachew et al., 2010). The overall adherence rate found in this study was much lesser than studies conducted in several parts of Ethiopia, which ranges from 72.4 to 79.3 (Amberbir Woldemichael et al., 2008; Tiyou Belachew et al., 2010). This may be partly attributed lowest level of the health facility in which the service is rendered. Health center in Ethiopian health care system is operated by low level health professional.

Alcohol non-users were 4 times more likely to adhere than alcohol users $(\mathrm{AOR}=4.36,95 \% \mathrm{Cl}=2.03,9.35)$. Alcohol use was significant predictor of non- adherence in many other studies. A prospective study conducted in USA revealed dose adherence rate for alcohol drinkers and non-drinkers were $66 \%$ and $74 \%$ respectively and adherence decreased by $8 \%$ among drinkers (Gardner Hullsiek et al., 2010). Alcohol use was a negative predictor of adherence in study conducted in south-west Ethiopia (Tessema Biadglegne et al., 2010). Alcohol use negative association with adherence is mostly referred to impaired judgment and forgetfulness.

Unlike to this finding, alcohol and substance use were not a significant negative predictor for adherence in cross sectional studies in Ethiopia (Amberbir Woldemichael et al., 2008; Markos Worku et al., 2008; Tiyou Belachew et al., 2010). This inconsistent finding may be partly attributed to missing the target groups (alcohol users) among study subjects.

Believing "ART cures HIVIAIDS" decreases the odds of adherence $2(\mathrm{AOR}=1.95,95 \% \mathrm{Cl}, 1.21,3.13)$. The false belief may encourage the patients cease taking medication after improved quality of life. A study conducted in a general population in Kisumu, Kenya a belief of "ART cures HIVIAIDS" were associated with an increased HIV sero-prevalence (Talam Gatongi et al., 2009). However we have not found studies used this variable to show its association with adherence in ART users.

Duration on HAART is another significant predictor observed in this study, duration greater than or equal to 49 months on treatment reduce the adherence by the odds of $70 \%(\mathrm{OR}=0.29,95 \% \mathrm{Cl}=0.11,0.75)$. As duration on treatment prolongs quality of life improve, clients' attention will be diverted to their daily routines than dosing their medication. Many studies reveal interest or motivation to adhere to medication will decrease when they have no symptom (Mathes Pieper et al., 2013; Nelsen Gupta et al., 2013; Rai Mahapatra et al., 2013). A study conducted in south-west Ethiopia, clients on WHO stage I are less likely to adhere to their treatment than
Sci. Technol. Arts Res. J., July-Sep 2014, 3(3): 93-98

advanced stages (COR=0.26, 95\% $\mathrm{Cl}=0.07,0.960)$ (Tiyou Belachew et al., 2010). Having good quality of life is therefore associated with impaired adherence because of the false perception of complete cure. TB co-infection and its treatment have negative impact on adherence to antiretroviral therapy (Eyasu Mengistu et al., 2012). How such condition was not considered in this study.

Social support may enhance adherence through encouragement, reassurance, reinforcement, systematic cues, bolstering of competence, and motivation, or by masking the effect of stress, anxiety, and depression (Tadios and Davey, 2006; Eyasu Mengistu et al., 2012). Family support was associated with adherence in the bivariate model of this study $(\mathrm{COR}=1.80,95 \% \mathrm{Cl}=1.07$, 3.01). However there was no significant association with adherence in the multivariate model. This might be due to the effect of confounders and smaller sample size. Other studies conducted in Ethiopia witnessed clients with family support were more likely to adhere than those who didn't get family support (Amberbir Woldemichael et al., 2008; Tiyou Belachew et al., 2010).

\section{CONCLUSIONS}

Overall adherence rate in this study is lower than many other studies conducted in Ethiopia. Alcohol use, a longer duration on treatment and false belief "ART cures HIV" were negative predictors of adherence while social support was positive predictor in this study. Proper and uninterrupted counseling during initiation of therapy and follow-up visits are highly needed. Interventions should target on reduction of alcohol use and on imparting appropriate knowledge of ART that will address false beliefs of "ART cures HIV".

\section{ACKNOWLEDGEMENTS}

We would like to thank Sheka Zone Health Department, Tepi Town Administration Health Unit and Tepi Health Center ART clinic staffs for their collaboration in data collection.

\section{REFERENCES}

Amberbir, A., Woldemichael, K., Sofonias Getachew., Belaineh Girma and Kebede Deribe (2008). Predictors of adherence to antiretroviral therapy among HIV-infected persons: a prospective study in Southwest Ethiopia." BMC Public Health 8: 265.

Arage, G., Tessema, G.A. and Hiwot Kassa (2014). Adherence to antiretroviral therapy and its associated factors among children at South Wollo Zone Hospitals, Northeast Ethiopia: a cross-sectional study. BMC Public Health 14(1): 365.

Biressaw, S., Abegaz, W.E., Markos Abebe, Workeabeba Abebe Taye and Mulugeta Belay (2013). Adherence to Antiretroviral Therapy and associated factors among HIV infected children in Ethiopia: unannounced home-based pill count versus caregivers' report. BMC Pediatrics 13: 132.

Cooke, C.E., Lee, H.Y. and Xing, S. (2014). Adherence to antiretroviral therapy in managed care members in the United States: a retrospective claims analysis. Journal of Managed Care Pharmacy 20(1): 86-92.

Deribe, K., Hailekiros, F., Biadgilign, S., Amberbir, A. and Beyene, B.K. (2008). Defaulters from antiretroviral treatment in Jimma University Specialized Hospital, 


\section{Tsion Debito and Serawit Deyno}

Southwest Ethiopia. Tropical Medicine \& International Health 13(3): 328-333.

Dewing, S., Mathews, C., Geoffrey Fatti, Ashraf Grimwood and Andrew Boulle (2014). Antiretroviral adherence interventions in Southern Africa: implications for using HIV treatments for prevention. Current HIVIAIDS Reports 11(1): 63-71.

Edison, L., Hughes, D., Cherie Drenzek. and Jane Kelly. (2014). Prevalence and Indicators of Viral Suppression Among Persons with Diagnosed HIV Infection Retained in Care - Georgia. 2010. Morbidity and Mortality Weekly Report (MMWR) 63(3): 55-58.

Emiru, A. and Wakgari, D. (2014). Acceptability of Provider Initiated HIV Counseling and Testing among Tuberculosis and Non-tuberculosis Patients in Shashemene Town, Ethiopia. Science Technology and Arts Research Journal 3(1): 116-121.

Eyasu, E., Mengistu, L., Ameni, G. (2012). Preliminary Study on the Epidemiology of Tuberculosis in Nekemte and Its Surroundings -Western Ethiopia. Science Technology and Arts Research Journal 1(1): 18-25.

Gardner, E., Hullsiek, K., Telzak, E.E., Sharma, S., Peng, G., Burman, W.J., MacArthur, R.D., Chesney, M., Friedland, G. and Mannheimer, S.B. (2010). Antiretroviral Medication Adherence and Class-Specific Resistance in a Large Prospective Clinical Trial. AIDS 24(3): 395-403.

Hassan, A. S., Nabwera, H.M., Shalton M. Mwaringa., Clare A. Obonyo., Eduard, J. Sanders., Tobias F Rinke de Wit., Patricia A. Cane and James A. Berkley (2014). HIV-1 virologic failure and acquired drug resistance among firstline antiretroviral experienced adults at a rural HIV clinic in coastal Kenya: a cross-sectional study. AIDS Research Therapy 11(1): 9.

Kebede, A. and Wabe, N.T. (2012). Medication adherence and its determinants among patients on concomitant tuberculosis and antiretroviral therapy in South west Ethiopia. North American Journal of Medical Sciences 4(2): 67-71.

Lee, L., Rand, C.S., Ellen, J.M. and Agwu, A.L. (2014). Factors Informing HIV Providers' Decisions to Start Antiretroviral Therapy for Young People Living With Behaviorally Acquired HIV. Journal of Adolescent Health 55(3):358-365.

Maqutu, D., T. Zewotir, North, D., Naidoo, K. and Grobler, A. (2011). Determinants of optimal adherence over time to antiretroviral therapy amongst HIV positive adults in South Africa: a longitudinal study. AIDS Behavior 15(7): 1465-1474.

Markos, E., Worku, A. and Davey, G. (2008). Adherence to ART in PLWHA at Yirgalem Hospital, South Ethiopia. Ethiopian Journal Health Development 22(2).

Mathes, T., Pieper, D., Antoine, S.L. and Eikermann, M. (2013). Cost-effectiveness of adherence interventions for highly active antiretroviral therapy: a systematic review. International Journal of Technology Assessment in Health Care 29(3): 227-233.
Sci. Technol. Arts Res. J., July-Sep 2014, 3(3): 93-98

Mengistu, Z. and Chere, A. (2012). Adherence to antiretroviral therapy and its associated factors among people living with HIV/AIDS in Addis Ababa, Ethiopia. Ethiopian Medical Journal 50(4): 355-361.

Michel, D., Lionel, P., Grappin, M., Forte, F., Peytavin, G., Buisson, M., Chavanet, P. and Portier, H. (2001). Evaluation of the Patient Medication Adherence Questionnaire As a Tool for Self-Reported Adherence Assessment in HIV-Infected Patients on Antiretroviral Regimens. HIV Clinical Trials 2(2): 128-135.

Miller, L. and Hays, R. (2000). Measuring adherence to antiretroviral medications in clinical trials. HIV Clinical Trials 1(1): 36-46.

Mirkuzie, A. H., Hinderaker, S.G., Sisay, M.M., Moland, K.M. and Mørkve, O. (2011). Current status of medication adherence and infant follow up in the prevention of mother to child HIV transmission programme in Addis Ababa: a cohort study. Journal of the International AIDS Society 14: 50

Mulu, A., Liebert, U.G. and Melanie Maier (2014). Virological efficacy and immunological recovery among Ethiopian HIV-1 infected adults and children. BMC Infectious Diseases 14: 28.

Nelsen, A., Gupta, S., Trautner, B.W., Petersen, N.J., Garza, A., Giordano, T.P., Naik, A.D. and Rodriguez-Barradas, M.C. (2013). Intention to adhere to HIV treatment: a patient-centred predictor of antiretroviral adherence. HIV Medicine 14(8): 472-480.

Bidhubhusan Mahapatra, Bharat Bhusan Rewari, Subhashish Sircar, Sandeep Rai, Srinivasan Venkatesh, Pinnamaneni Yujwal Raj, and Mohammed Shaukat (2013). Adherence to Antiretroviral Therapy and Its Effect on Survival of HIVInfected Individuals in Jharkhand, India. PLOS ONE 8(6): e66860.

Tadios, Y. and Davey, G. (2006). Antiretroviral treatment adherence and its correlates in Addis Ababa, Ethiopia." Ethiopian Medical Journal 44(3): 237-244.

Talam, N. C., Gatongi, P.M., Rotich J.K. and Kimaiyo, S. (2009). Adherence to antiretroviral drug therapy by adult patients attending HIV/AIDS clinic at a Kenyan tertiary health institution. East African Medical Journal 86(5): 240243.

Tessema, B., Biadglegne, F., Andargachew Mulu., Assefa Getachew., Frank Emmrich and Ulrich Sack. (2010). Magnitude and determinants of nonadherence and nonreadiness to highly active antiretroviral therapy among people living with HIV/AIDS in Northwest Ethiopia: a cross-sectional study. AIDS Research Therapy 7: 2

Tiyou, A., Belachew, T., Fisehaye Alemseged and Sibhatu Biadgilign. (2010). Predictors of adherence to antiretroviral therapy among people living with HIV/AIDS in resource-limited setting of southwest Ethiopia. AIDS Research Therapy 7: 39. 